\title{
ANÁLISE DA VIABILIDADE DE IMPLANTAÇÃO DE UM AEROGERADOR DO TIPO DARRIEUS PARA GERAÇÃO DE ENERGIA ELÉTRICA EM ANCHILO
}

\section{ANALYSIS OF THE FEASIBILITY OF IMPLEMENTING AN DARRIEUS TYPE AEROGENERATOR FOR ELECTRICITY GENERATION IN ANCHILO}

Paulo Baptista Alface Licenciado em Ensino de Física com habilitações em Energias Renováveis, Universidade Rovuma (UniRovuma), Moçambique E-mail: paulobaptistaalface@gmail.com

António Gonçalves Fortes

Doutorando em Geociências, Mestre em Engenharia Geológica, Especialista em Energias Renováveis, Licenciado em Ensino de Física, UniRovuma, Moçambique E-mail: antoniogoncalves.fortes@yahoo.com

Momade Jaime Chau Mestrando em Educação/Ensino de Ciências Naturais, Licenciado em Ensino de Física, UniRovuma, Moçambique E-mail: $\underline{\text { mchau@unirovuma.ac.mz }}$

Alcido Alberto João Licenciado em Ensino de Física com habilitações em Energias Renováveis, UniRovuma, Moçambique E-mail: alcidocarolina@gmail.com

Recebido: 10/05/2021 - Aceito: 10/05/2021

\section{Resumo}

A geração eólica de eletricidade constitui uma alternativa ambiental e econômica para eletrificação das áreas rurais e isoladas, não abrangidas pela energia da rede. $O$ uso de aerogeradores alternativos pode contribuir no desenvolvimento socioeconômico e na redução dos impactos 
ambientais e da pobreza energética que assola a população da África subsaariana e moçambicana em particular. Neste contexto, realizou-se um estudo experimental e de campo com objetivo de analisar a viabilidade técnica e econômica da geração de eletricidade através de um aerogerador do tipo Darrieus, construído a partir de materiais alternativos e testado no posto administrativo de Anchilo - cidade de Nampula, Moçambique, durante 3 dias com condições meteorológicas adversas. Constatou-se que em Anchilo existe um potencial eólico para geração de eletricidade em pequena escala. O protótipo construído é econômico e implantado a 2,6 $\mathrm{m}$ de altura em relação ao solo, gerou, respectivamente a tensão, corrente, potência elétrica e eficiência de até $10.3 \mathrm{~V}, 1.21 \mathrm{~A}$, $12,4 \mathrm{~W}$ e $30 \%$, sem impactos ambientais consideráveis. Concluiu-se que o aerogerador construído a partir de materiais alternativos e implantado próximo às comunidades, apresenta viabilidade técnica, econômica e ambiental na geração de eletricidade para uso em pequenos consumidores, em sistemas off grid.

Palavras-chave: Energia eólica; Aerogerador; Sustentabilidade energética; sistemas alternativos.

\section{Abstract}

Wind power generation is an environmental and economic alternative for electrifying rural and isolated areas, which are not covered by the grid energy. The use of alternative wind turbines can contribute to socioeconomic development and to the reduction of environmental impacts and energy poverty that plagues the population of sub-Saharan Africa and Mozambican in particular. In this context, an experimental and field study was carried out to analyze the technical and economic feasibility of electricity generation through a wind turbine of the Darrieus type, built from alternative materials and tested at the administrative post of Anchilo- city of Nampula, Mozambique, for 3 days with adverse weather conditions. It was found that in Anchilo there is a wind potential for electricity generation on a small scale. The prototype built is economical and deployed at a height of $2.6 \mathrm{~m}$ in relation to the ground, generating, respectively, voltage, current, electrical power and efficiency of up to $10.3 \mathrm{~V}, 1.21 \mathrm{~A}, 12.4 \mathrm{~W}$ and $30 \%$, without considerable environmental impacts. It was concluded that the wind turbine built with alternative materials and deployed near the communities, presents technical, economic and environmental feasibility in the generation of electricity for use in small consumers, in off grid systems.

Keywords: Wind energy; Wind generator; Energy Sustainability; Alternative systems.

\section{Introdução}

A energia eólica (do grego antigo Oỉołúkos/Oíolúkos, aeolicus, relativo à Éolo, Deus dos ventos na mitologia grega) é a transformação da energia cinética do vento em energia cinética de rotação e translação dos aerogeradores (conversão elétrica) ou cata-ventos e moinhos (conversão mecânica). Trata-se de uma abundante fonte de energia limpa, renovável e disponível em vários locais (PINTO, 2012). Esta energia pode ser convertida de diversas formas. Uma das primeiras conversões utilizadas até hoje é a conversão da energia potencial do vento em energia mecânica. Esta forma de energia tem sido utilizada a milhares de anos para o bombeamento de água, moagem de grãos, mover barcos, drenagem de 
terras alagadas para cultivo ou construção e, atualmente, para gerar energia mecânica e/ou elétrica (REIS, 2011; SILVA, 2006).

Os aerogeradores são sistemas de geração eólica acoplados a um catavento para converter a energia cinética de vento em energia elétrica. Eles foram inicialmente utilizados na Pérsia, China e Médio Oriente, para trabalhos agrícolas e, atualmente, são utilizados, de forma síncrona, para geração de eletricidade. $O$ aerogerador de eixo vertical do tipo Darrieus é capaz de gerar eletricidade em condições de ventos moderados, isto é, com uma velocidade de arranque baixa e sem necessidade de inclusão do mecanismo de direcionamento, aproveitando-se o regime do vento em qualquer direção (DUTRA, 2009; SOUSA, 2014).

Ao longo das últimas décadas, a nível mundial, houve aumento na geração elétrica através de sistemas eólicos, atingindo cerca de $600 \mathrm{GW}$ por ano, desde 2018. Em Moçambique, foram confirmados ao longo de mais de um ano de medições, 16 locais com um total de 4,5 gigawatts (GW) de potencial eólico no Centro e Sul do país (GUEIFÃO et al., 2013). Destes, cerca de 1,1 GW de potencial e projetos eólicos apresentam viabilidade de ligação à rede (sistema on grid) e equivalentes de produção entre 2.300 e 3.900 horas, com destaque para a região Sul do país e próximo aos consumidores (ALER, 2017; GUEIFÃO et al., 2013). Os restantes 3,4 GW de potenciais projetos eólicos identificados apresentam como principal constrangimento ao seu desenvolvimento a débil rede elétrica nacional (ALER, 2017). Nesta ótica, entende-se que há necessidades de se inovar no setor energético, com vista a obter sistemas mais eficientes e sustentáveis.

A pesquisa poderá contribuir no desenvolvimento socioeconômico e na redução da pobreza energética que assola a população da África subsaariana e moçambicana em particular, sobretudo das regiões rurais e suburbanas não abrangidas pela energia da rede nacional (ERN), para além de trazer uma nova visão sobre o aproveitamento do potencial eólico disponível, usando-se tecnologias energéticas alternativas, de baixo custo e menos poluentes ao meio ambiente.

Assim sendo, o presente trabalho teve como objetivo analisar a viabilidade técnica e econômica da geração de energia elétrica através de um aerogerador de eixo vertical do tipo Darrieus, construído com material alternativo e de fácil acesso. Com o sistema pretende-se ainda, auxiliar a população rural e isolada, na melhoria 
da qualidade e diminuição das taxas de ERN fornecida em Anchilo e disponibilizar serviços energéticos sustentáveis para a população da cidade de Nampula.

\section{Revisão da Literatura}

\subsection{Energia Eólica}

O vento é uma massa de ar em movimento, gerada pelo aquecimento diferenciado das camadas de ar pelo Sol (diferentes humidades, temperaturas e de pressões) e os movimentos relativos da Terra (diferentes velocidades e direções do vento) (REIS, 2011). A principal característica do vento é sua intermitência. Em intervalos de horas, dias e meses, variações de intensidade e direção são notadas nos regimes de vento. Diversas técnicas são empregadas para registar dados como velocidade e direção dos ventos, como forma de tentar descobrir padrões no comportamento temporal e local do vento (DUTRA, 2009; PINTO, 2012).

A energia eólica é vista como uma das fontes de energia mais importantes para o século XXI. O relatório sobre as perspectivas para a Energia Eólica Global, indica que, em 2050, um terço da eletricidade global poderá ser fornecida pelo vento, o que impediria a emissão de 113 milhões de toneladas de $\mathrm{CO}_{2}$ para a atmosfera nesse período (MARTINS et al., 2008; SILVA et al., 2017).

A seguir, apresenta-se as vantagens e desvantagens da energia eólica (tabela 1).

Tabela 1: Vantagens e desvantagens da energia eólica.

\begin{tabular}{|c|c|}
\hline Vantagens & Desvantagens \\
\hline $\begin{array}{l}\text { - É um recurso limpo e renovável; } \\
\text { - Não emite GEE e não gera resíduo; } \\
\text { - É abundante na natureza; } \\
\text { - O terreno ocupado pelos parques eólicos } \\
\text { pode ser utilizado para outros fins, como a } \\
\text { - agricultura e a criação de gado; } \\
\text { - Reduz a dependência energética do exterior; } \\
\text { - Há desenvolvimento de tecnologias mais } \\
\text { - eficientes e uma competitividade no preço; } \\
\text { - Pouca manutenção e elevada eficiência; } \\
\text { - Fontes baratas de energia; } \\
\text { - Criação de emprego para a população local. }\end{array}$ & $\begin{array}{l}\text { - A geração de energia depende da } \\
\text { disponibilidade do recurso eólico; } \\
\text { - Custo inicial alto; } \\
\text { - Quando a produção está afastada dos } \\
\text { grandes centros urbanos, exige-se } \\
\text { maiores investimentos em linhas de } \\
\text { transmissão; } \\
\text { - Interferências eletromagnéticas; } \\
\text { - Poluição sonora e visual; } \\
\text { - Intermitência } \\
\text { - Impacto ambiental (migração das aves). }\end{array}$ \\
\hline
\end{tabular}

Fonte: (SILVA, 2006, p. 29). 


\subsection{Geradores eólicos do tipo Darrieus}

Aerogerador é um gerador elétrico integrado ao eixo de um cata-vento e que converte energia eólica em energia elétrica. No aerogerador, parte da energia cinética do vento é absorvido através de um rotor aerodinâmico (Fig. 1), que converte em potência mecânica de eixo (torque x rotação), a qual é convertida em potência elétrica (tensão x corrente) (DUTRA, 2009; SILVA, 2006).

Um aerogerador é constituído por vários componentes que devem trabalhar em consonância, de forma a propiciar um maior rendimento final (PINTO, 2012; SOUZA, 2018). Para efeito de estudo, considerou-se os seguintes componentes:

- Vento: disponibilidade energética destinado à instalação do sistema eólico;

- Rotor: converte a energia cinética do vento em energia mecânica de rotação;

- Transmissão e caixa multiplicadora: transmite a energia mecânica entregue pelo eixo do rotor até a carga ou acoplado diretamente a carga;

- Gerador elétrico: converte a energia mecânica em elétrica;

- Mecanismo de controlo: orienta o rotor, controle de velocidade, controle da carga entre outros;

- Torre de sustentação: sustenta e posiciona o rotor na altura conveniente;

- Transformador: acoplamento elétrico entre o aerogerador e a rede elétrica; Os aerogeradores são classificados pela posição do eixo do seu rotor, que pode ser horizontal ou vertical (Fig. 1).

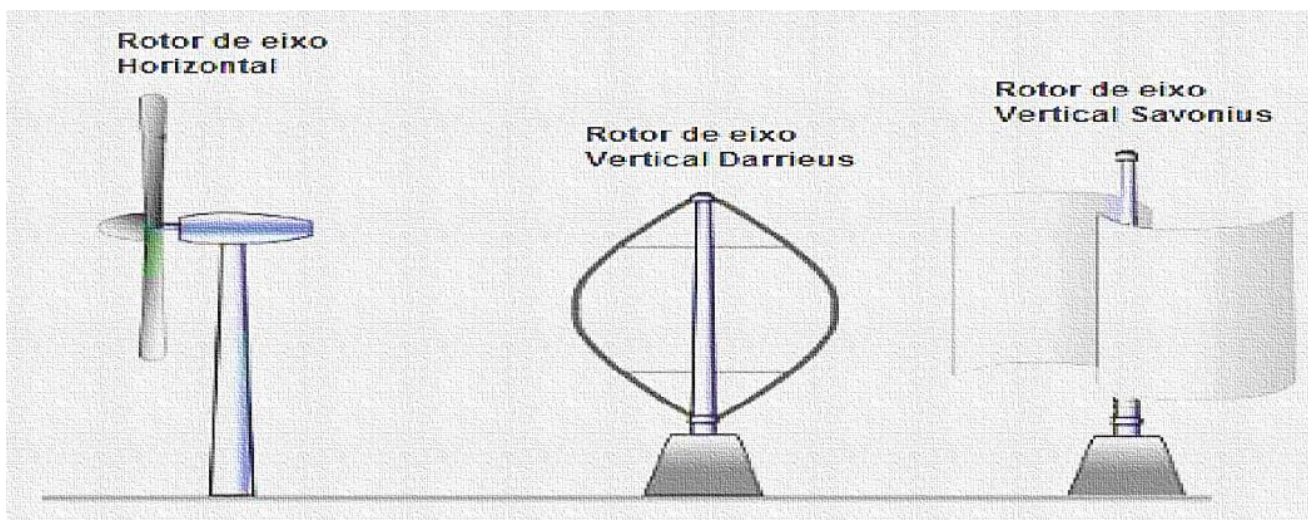

Figura 1: Tipos de rotores de aerogeradores. Fonte: (SOUZA, 2018, p. 26). 
Os rotores de eixo vertical têm seu eixo de rotação perpendicular à direção do vento, operando com ventos de qualquer direção, eles tendem a duas configurações principais, Savonius e Darrieus (SOUSA, 2014). No primeiro caso, a energia é gerada utilizando a transferência de quantidade de movimento e, no segundo, usando forças aerodinâmicas. O rotor Savonius é caracterizado pelo seu alto torque, baixa velocidade e baixa eficiência, e o rotor Darrieus se caracteriza pela sua elevada velocidade e alta eficiência (SOUSA, 2014; SOUZA, 2018).

As turbinas verticais do tipo Darrieus foram inventadas na década de 1920, porém só foram desenvolvidas na década de 1970. Normalmente, esse sistema usa o gerador como motor para rotacionar o rotor até que se atinja a velocidade suficiente para começar a geração de energia. Apesar da solução relativamente simples, isso implica no requisito de uma caixa de marchas bidirecional, aumentando o custo da turbina (PINTO, 2012; SOUSA, 2014; SOUZA, 2018).

Existem três tipos de rotores Darrieus, nomeadamente (Fig. 2): rotor Darrieus cilíndrico, rotor Darrieus H e rotor Darrieus Helicoidal.
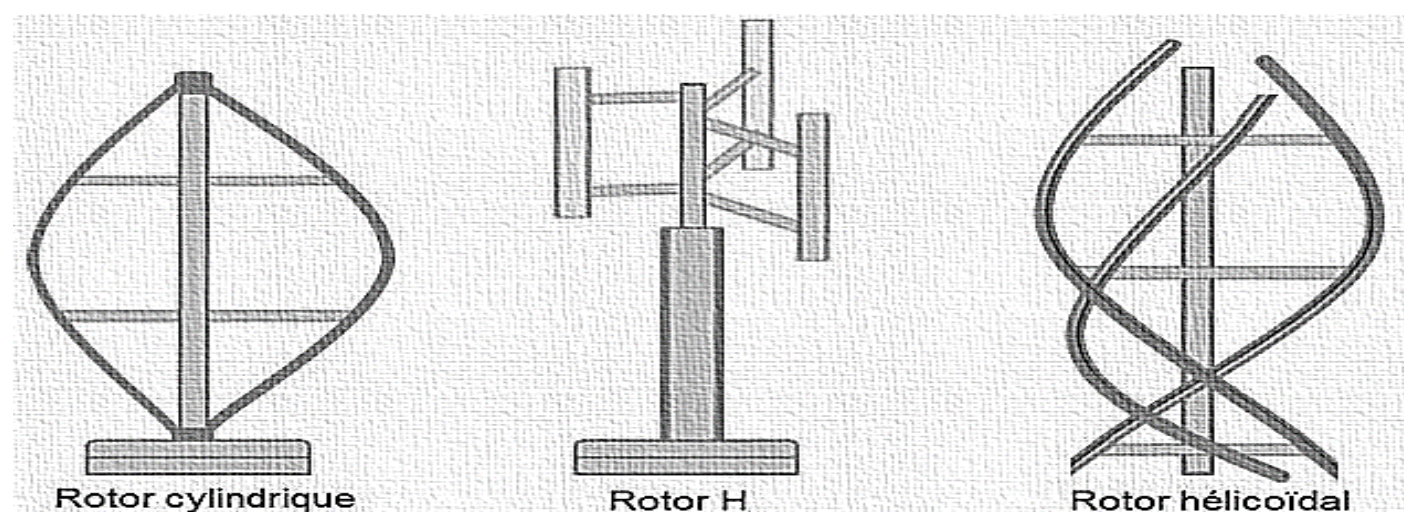

Figura 2: Turbina Darrieus e suas variantes. Fonte: (SOUZA, 2018, p. 37).

Durante o seu funcionamento, as turbinas do tipo Darrieus apresentam as seguintes vantagens e desvantagens (tabela 2). 
Tabela 2: Vantagens e desvantagens das turbinas do tipo Darrieus

\begin{tabular}{|c|c|}
\hline Vantagens & Desvantagens \\
\hline $\begin{array}{l}\text { - Não necessitam de mecanismos } \\
\text { direcionais; } \\
\text { - As pás são fixas nos dois } \\
\text { extremos do eixo, reduzindo o } \\
\text { esforço estrutural; } \\
\text { - As turbinas de eixo vertical são } \\
\text { montadas mais próximas ao solo; } \\
\text { - São de construção simples e têm } \\
\text { alta eficiência energética; } \\
\text { - Funcionam com ventos de } \\
\text { qualquer direção. }\end{array}$ & $\begin{array}{l}\text { - As turbinas de sustentação requerem um sistema de } \\
\text { partida para o acionamento em baixas velocidades; } \\
\text { - Perdem captura de energia em terrenos complexos; } \\
\text { - As turbinas eólicas de eixo vertical são muito difíceis } \\
\text { de serem instaladas em torres, por isso elas devem } \\
\text { ser instaladas em bases, como terreno ou prédio; } \\
\text { - Em decorrência do movimento de rotação de suas } \\
\text { pás, altera constantemente os ângulos de ataque, } \\
\text { assim como o seu deslocamento em relação à } \\
\text { direção dos ventos, o que limita o seu rendimento e } \\
\text { causa acentuada vibração em toda sua estrutura. }\end{array}$ \\
\hline
\end{tabular}

Fonte: (SILVA, 2006, p. 29).

\subsection{Potencial eólico da cidade de Nampula}

Moçambique detém de um considerável potencial em recursos energéticos, o que proporciona condições favoráveis, não só para satisfazer a procura interna, como também na exportação para os países da região da África Austral.

O país apresenta um regime de ventos de intensidade média-baixa com velocidades predominantemente entre os $4-6 \mathrm{~m} / \mathrm{s}$ a 80 metros acima do nível do solo, com exceção da zona Sul do país e das zonas altas no Centro e Norte, onde os ventos atingem valores mais elevados (GUEIFÃO et al., 2013). Mesmo com um potencial de geração de 4,5 GW comprovado, o mercado da energia eólica encontra-se numa fase inicial de desenvolvimento sem qualquer contributo para a matriz energética do país (ALER, 2017; GUEIFÃO et al., 2013).

O não aproveitamento do recurso eólico na sua total potencialidade, deve-se a quatro fatores essenciais: (i) falta de experiência e conhecimento no país para operar com a energia eólica; (ii) existência de poucos locais no país onde o vento é suficientemente constante para justificar a implantação de projetos; (iii) alto custo de aquisição do equipamento; e (iv) logística de transporte e armazenamento do equipamento, tendo em conta o dimensionamento geográfico do país, torna necessário percorrer longas distâncias em vias de acesso e infra estruturas degradadas (FORTES et al., 2020; GUEIFÃO et al., 2013). Por isso, é menos 
provável o desenvolvimento de projetos eólicos do que o de outras fontes, pois pela sua complexidade logística estão mais dependentes de economias de escala.

A velocidade horária média do vento em Nampula passa por variações sazonais significativas ao longo do $a n 0^{1}$. A época de mais ventos no ano dura 3.8 meses, de 10 de agosto a 3 de dezembro, com velocidades médias do vento acima de $12.4 \mathrm{~km} / \mathrm{h}$. O dia de ventos mais fortes do ano é 12 de outubro, com $15.3 \mathrm{~km} / \mathrm{h}$ de velocidade média horária de vento. E a época mais calma do ano dura 8.2 meses, de 3 de dezembro a 10 de agosto. O dia mais calmo do ano é 5 de março, com $9.5 \mathrm{~km} / \mathrm{h}$ de velocidade horária média do vento.

Para além das características dinâmicas do vento, a potência e o rendimento do aerogerador dependem das características das pás, do eixo do rotor e do tipo de gerador usado. A tabela 3, descreve os parâmetros mecânicos e elétricos a serem estimados e as suas respectivas expressões matemáticas.

Tabela 3: Parâmetros físicos para estimar a potência e a eficiência do sistema.

\begin{tabular}{|c|c|c|c|}
\hline Grandeza & Conceito & Fórmula & \\
\hline Energia total $\left(\mathrm{E}_{\mathrm{T}}\right)$ & $\begin{array}{l}\text { É potência total gerada }\left(P_{T}\right) \text { num } \\
\text { determinado intervalo de tempo de uso }(\mathrm{t}) \text {. }\end{array}$ & $E_{\tau}=P_{\tau} \times t$ & (1) \\
\hline $\begin{array}{l}\text { Potência do vento } \\
\qquad\left(\mathrm{P}_{\text {disp }}\right)\end{array}$ & $\begin{array}{l}\text { A potência disponível no vento, que } \\
\text { depende da densidade }\left(\rho_{\mathrm{a}}\right) \text {, da velocidade } \\
\text { do } \operatorname{ar}(u) \text { e da área varrida pelo vento }\left(\mathrm{A}_{\mathrm{s}}\right) \text {. }\end{array}$ & $P_{\text {disp }}=\frac{\rho_{a} \times u^{3} \times A_{s}}{2}$ & (2) \\
\hline $\begin{array}{l}\text { Velocidade de } \\
\text { rotação }(f)\end{array}$ & $\begin{array}{l}\text { É o número (n) de rotações do eixo da } \\
\text { turbina em função do tempo (t) de rotação. }\end{array}$ & $f=\frac{n}{t}$ & (3) \\
\hline $\begin{array}{l}\text { Potência do rotor } \\
\qquad\left(P_{R}\right)\end{array}$ & $\begin{array}{l}\text { A potência extraída pelo rotor. Ela depende } \\
\text { da massa do rotor }(m) \text {, do número de voltas } \\
(\mathrm{n}) \text {, do comprimento em relação ao diâmetro } \\
\text { do rotor (l), e do intervalo de tempo (t). }\end{array}$ & $P=\frac{m * l^{2}(2 \pi n)^{2}}{24 t^{2}}$ & (4) \\
\hline $\begin{array}{l}\text { Potência extraída } \\
\text { pelo gerador }\left(\mathrm{P}_{\mathrm{G}}\right)\end{array}$ & $\begin{array}{l}\text { A energia elétrica nos terminais do gerador, } \\
\text { ela é determinada conhecendo-se a tensão } \\
\text { gerada }(U) \text { e a intensidade da corrente (I). }\end{array}$ & $P=U \times I$ & (5) \\
\hline $\begin{array}{l}\text { Rendimento do } \\
\text { sistema }\left(\eta_{T}\right)\end{array}$ & $\begin{array}{l}\text { A energia que o sistema consegue extrair da } \\
\text { fonte eólica disponível }\end{array}$ & $\eta=\frac{P_{\text {ger }}}{P_{\text {disp }}} \times 100 \%$ & (6) \\
\hline
\end{tabular}

Fonte: Adaptado pelos Autores, 2021.

\footnotetext{
${ }^{1}$ Fonte: https://pt.weatherspark.com/y/101091/Clima-caracter\%C3\%ADstico-em-Nampula Mo\%C3\%A7ambique-durante-o-ano, acesso em 24-11-2020.
} 


\subsection{Avaliação do impacto ao meio ambiente}

Segundo a lei do ambiente $\mathrm{n}^{\circ}$ 20/97 de 1 de outubro, "o impacto ambiental é qualquer mudança do ambiente, para melhor ou para pior, especialmente com efeitos no ar, na terra e na saúde das pessoas, resultante de atividades humanas" (MOÇAMBIQUE, 1997, art 1, no 16). A mesma lei define avaliação de impacto ambiental (AIA) como sendo “... um instrumento de gestão ambiental preventiva $e$ consiste na identificação e análise prévia qualitativa e quantitativa dos efeitos ambientais benéficos e perniciosos de uma atividade proposta" (MOÇAMBIQUE, 1997, art 1, nํ18).

Os impactos ambientais podem advir de várias formas, desde a construção, a implantação e a desativação da usina, sobretudo a emissão de gases de efeito estufa (GEE) no ambiente, causados pela queima de matéria orgânica e inorgânica, eliminação de plantas para dar lugar a usina, ruídos e perda da flora e da fauna existentes na área circunvizinha (JOÃO et al., 2020). Mas Kemerich et al. (2011, p. 149) alertam que "Alguns impactos podem ser rapidamente excluídos da preocupação social, como é o caso da geração de ruídos e impacto visual, a partir da criação de uma camada vegetal que possa cercar o empreendimento".

Impactos socioambientais são mudanças sofridas pelo meio ambiente e que foram provocadas por determinadas ações ou atividades, impactando sobre a qualidade de vida, a saúde humana, economia urbana, modifica ainda mais o meio ambiente e os ambientes construídos (MOÇAMBIQUE, 1997). O impacto visual do aproveitamento eólico é inevitável devido às suas características técnicas nos locais de instalações. As usinas eólicas alteram claramente a paisagem e devem ser avaliadas de acordo com a situação prévia existente em cada localização tendo a intervenção direta da população sobre este impacto (SILVA, 2006).

\section{Materiais e métodos}

A pesquisa pode ser classificada como aplicada, de abordagem quantitativa, baseada nos métodos bibliográfico, experimental e o trabalho de campo. 
Neste estudo fez-se um levantamento e recolha de informações existentes, sem delimitação espacial e temporal, em diversas obras literárias, artigos científicos, monografias, dissertações e teses, que abordam, de os aspetos sobre o sistema eólico, como a potência do vento e os tipos de aerogeradores.

A pesquisa cingiu-se basicamente no método experimental que consistiu na construção, testagem e coleta de dados primários e dos parâmetros técnicos, durante três dias do funcionamento do sistema, em dois períodos por dia.

A construção e montagem do protótipo contou com os seguintes procedimentos:

- Na montagem do protótipo, primeiro construiu-se o rotor e pás usando tubo metálico de 1,5 mm de secção com $1 \mathrm{~m}$ de comprimento, um varão de $8 \mathrm{~mm}$ de secção, cantoneira de $4 \mathrm{~mm}$ de secção com comprimento de 2,5 m e um tubo PVC de 110 mm de secção (Fig. 3B e 3C);

- Para a montagem da torre de sustentação, usou-se barrotes de 1,6 m de comprimento e dois pedaços de tábua com $40 \times 30 \mathrm{~cm}$ (Fig. 3D).

- Para a montagem do gerador cortou-se uma tábua em dois pedaços com área de $15 \mathrm{~cm}^{2}$ e ripas com $15 \mathrm{~cm}$ de comprimento (Fig. 3A).
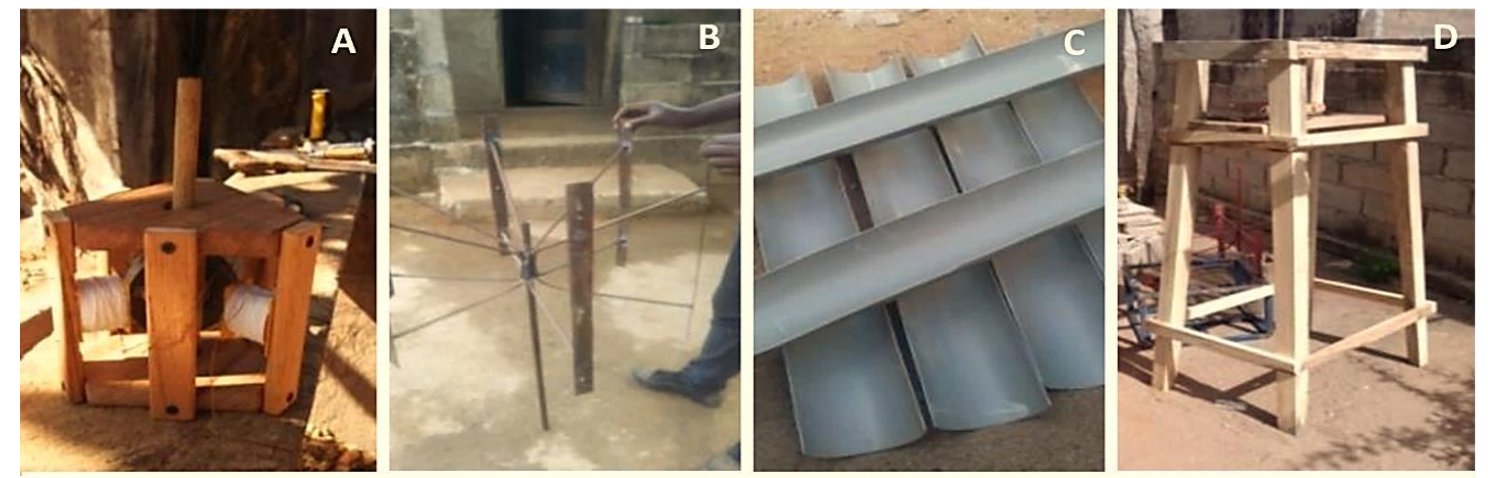

Figura 3: Partes do aerogerador: (A) aerogerador; (B) rotor; (C) pás com tubos policloreto de vinila (PVC); (D) torre de sustentação. Fonte: Autores, 2020.

A tabela 4 descreve a quantidade de materiais usados na construção do protótipo em estudo. 
Revista Multidisciplinar do Nordeste Mineiro, v.1,

2021/01

ISSN 2178-6925

Tabela 4: Materiais necessários para a construção de um Aerogerador (protótipo).

\begin{tabular}{|c|c|c|}
\hline № & Nome do material & Quantidade \\
\hline 01 & Madeira de $40 \times 40 \mathrm{~cm}$ & 2 \\
\hline 02 & Parafusos de 1,5 polegadas & 12 \\
\hline 03 & Imã de $1 \mathrm{~cm}$ de largura e espessura $8 \mathrm{~cm}$ diâmetro maior & 1 \\
\hline 04 & Tubo de aço de $1,5 \mathrm{~mm}$ & 1 \\
\hline 05 & Cantoneira de $3 \mathrm{~mm}$ & 1 \\
\hline 06 & Rolamentos & 4 \\
\hline 07 & Varão roscado de $10 \mathrm{~mm}$ & 1 \\
\hline 08 & Polias dentadas ou carretos & 2 \\
\hline 09 & Tubo PVC de $110 \mathrm{~mm}$ & 1 \\
\hline 10 & Fios de cobre $2 \mathrm{~mm}$ & 3 \\
\hline 11 & Núcleo para bobinagem & 1 \\
\hline 12 & Varão simples de $8 \mathrm{~mm}$ & 4 \\
\hline 13 & Anilhas de $2 \mathrm{~mm}$ & 6 \\
\hline 14 & Porcas & \\
\hline
\end{tabular}

Fonte: Autores, 2020.

O trabalho de campo consistiu em implantar o protótipo no local de estudo. Antes, analisou-se as características físicas do local, como o relevo, a fauna e a flora para a definição dos pontos com melhor circulação de vento e fora das propriedades particulares vedadas. Utilizou-se o multímetro, para medir a intensidade da corrente e tensão gerada. Os dados sobre a velocidade do vento no local foram fornecidos pela Instituto Nacional de Meteorologia - Nampula.

\section{Resultados e discussão}

\subsection{Descrição do local em estudo}

O posto administrativo de Anchilo localiza-se no distrito de Nampula (Fig. 4), ao longo da Estrada Nacional $n \circ 8$ (EN8) que liga as cidades de Nampula e Nacala. O local de estudo está na latitude $-15,0976 \mathrm{E}$, longitude 39,4249 S. 

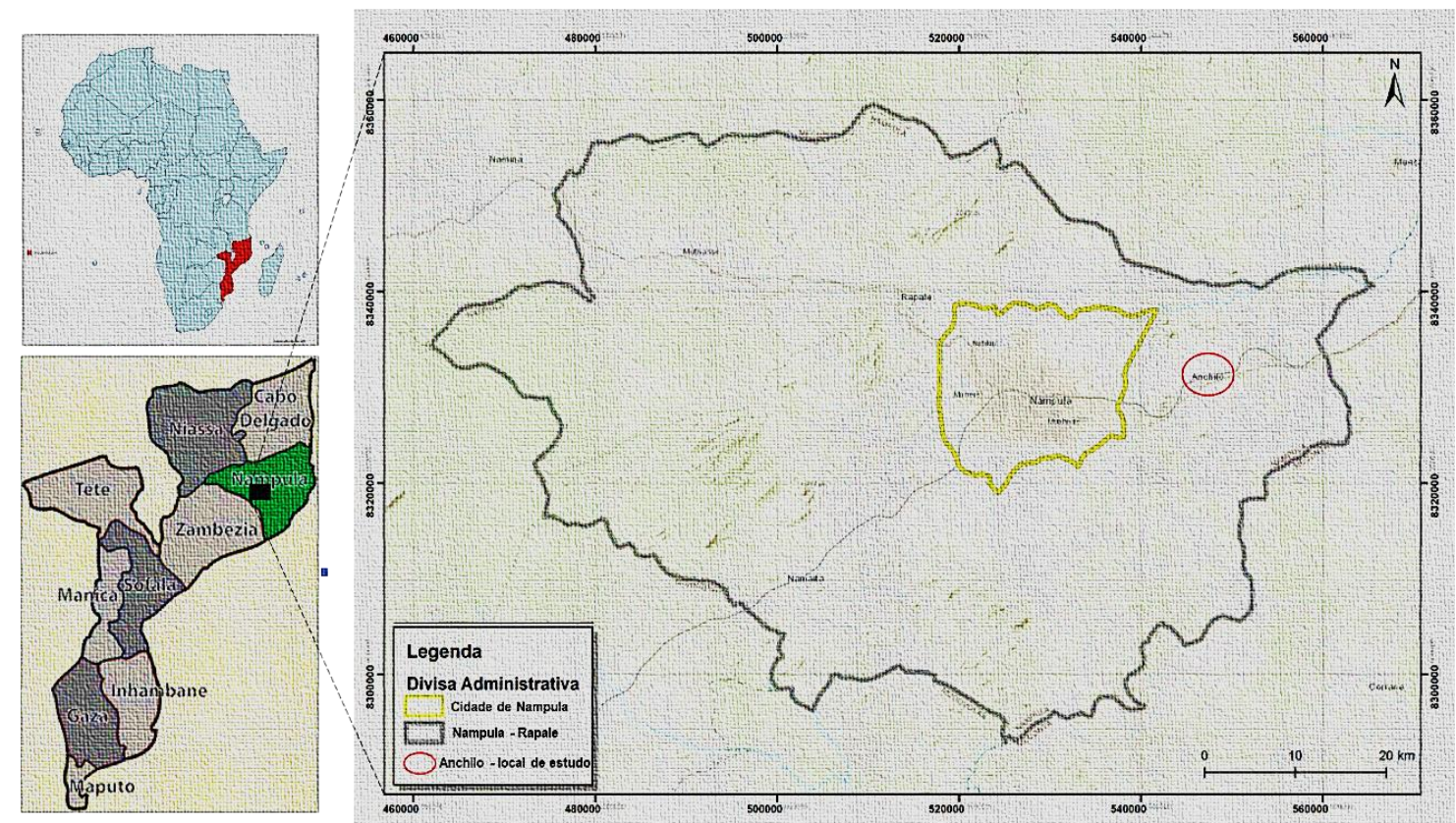

Figura 4: Localização geográfica do posto administrativo de Anchilo. Fonte: Autores, 2021.

O local onde foi implantado o protótipo em estudo (Fig. 5) faz fronteiras com uma área residencial (a Oeste), área de cultivo (a Norte e Leste) e um campo de futebol 11 (a Sul). O local é dimensionado em cerca de 2 hectares de área plana, com solo castanho, usado como área de cultivo de plantas alimentícias, apresentando-se com cobertura de relva, plantas de pequeno porte e algumas árvores frutíferas no extremo residencial (Fig. $5 \mathrm{~A}$ ).

O protótipo foi testado num extremo distante da área residencial (Fig. 5 B) para diminuir a interferência destas na circulação do vento. A altura do protótipo em relação ao solo foi de 2,6 m e não foi necessário limpar a área, nem cavar o solo para implantar o sistema. Quanto ao seu funcionamento, não necessitou um impulso inicial para o seu arranque, pois o vento tinha energia suficiente para tal. 

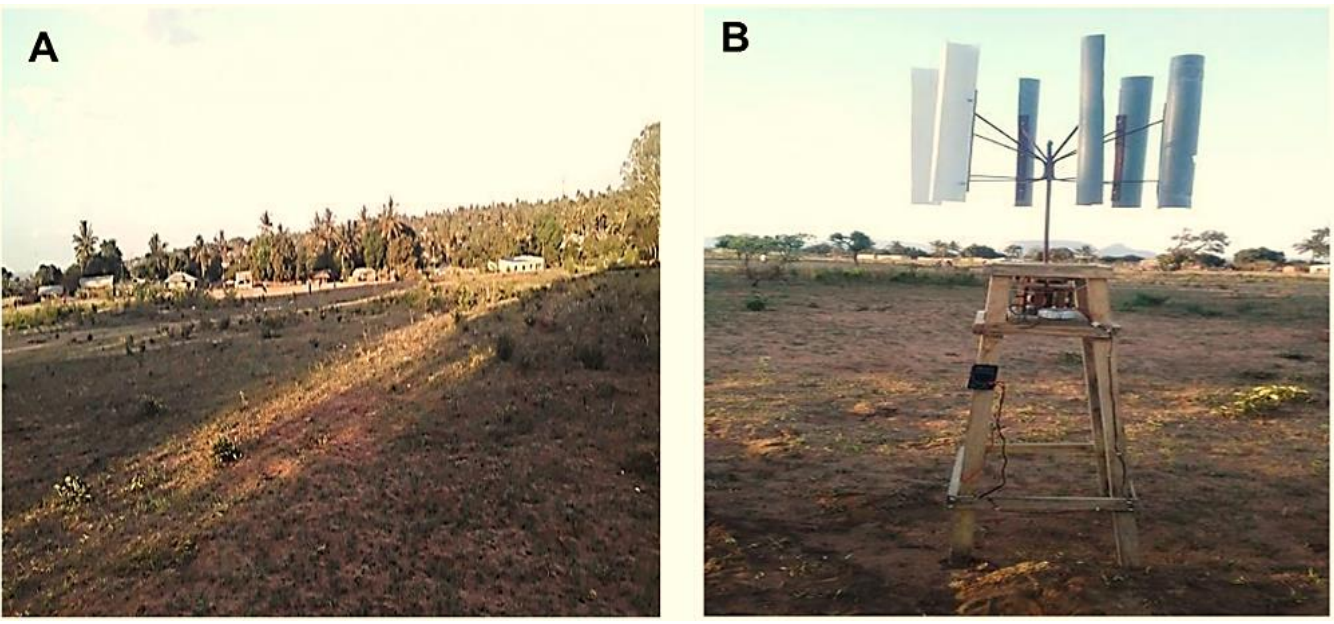

Figura 5: Local de estudo: (A). local implantado o protótipo; (B) o protótipo no local de estudo. Fonte: Autores, 2020.

Os trabalhos experimentais foram realizados em três dias com condições meteorológicas adversas (tabela 5), com vista a avaliar o impacto que as diferenças da temperatura e velocidade do vento têm no local da geração elétrica.

A velocidade média do vento (Fig. 6) e a temperatura (Fig. 7) no local podem ser favoráveis para o aproveitamento da energia eólica para geração de eletricidade ou para bombeamento de água e regadio de plantas.

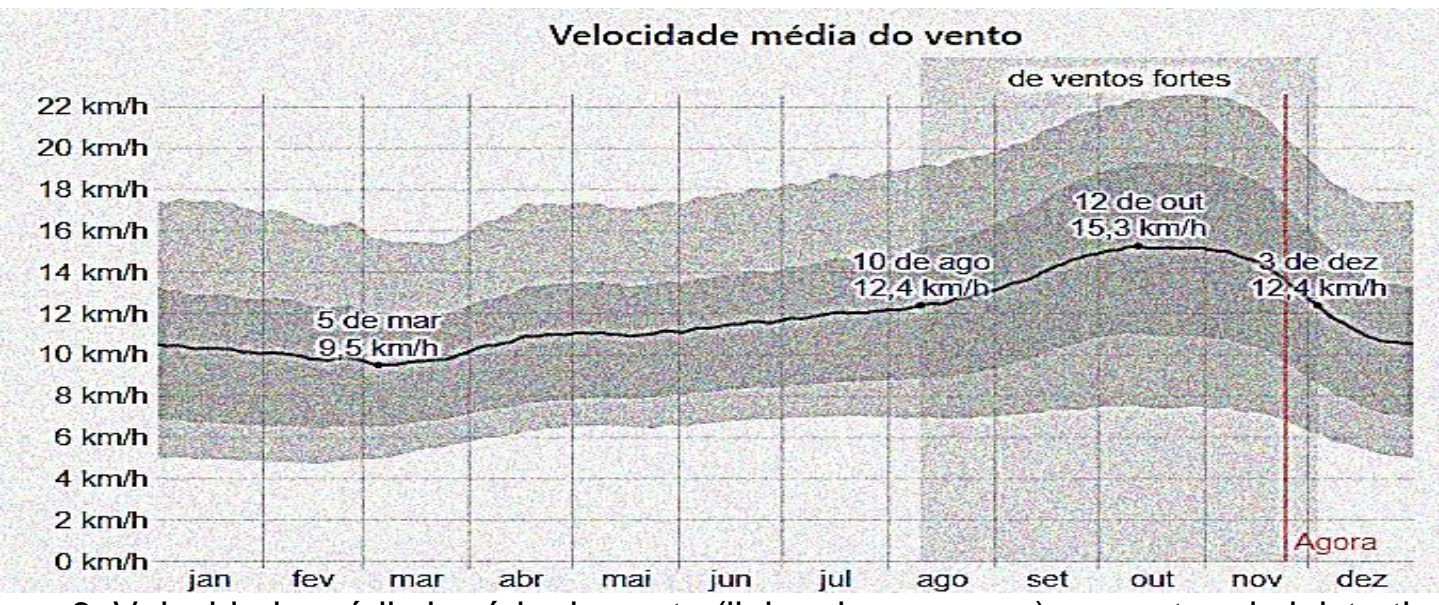

Figura 6: Velocidade média horária do vento (linha cinza-escuro) no posto administrativo de Anchilo ${ }^{2}$, com faixas do $25^{\circ}$ ao $75^{\circ}$ e do $10^{\circ}$ ao $90^{\circ}$. 


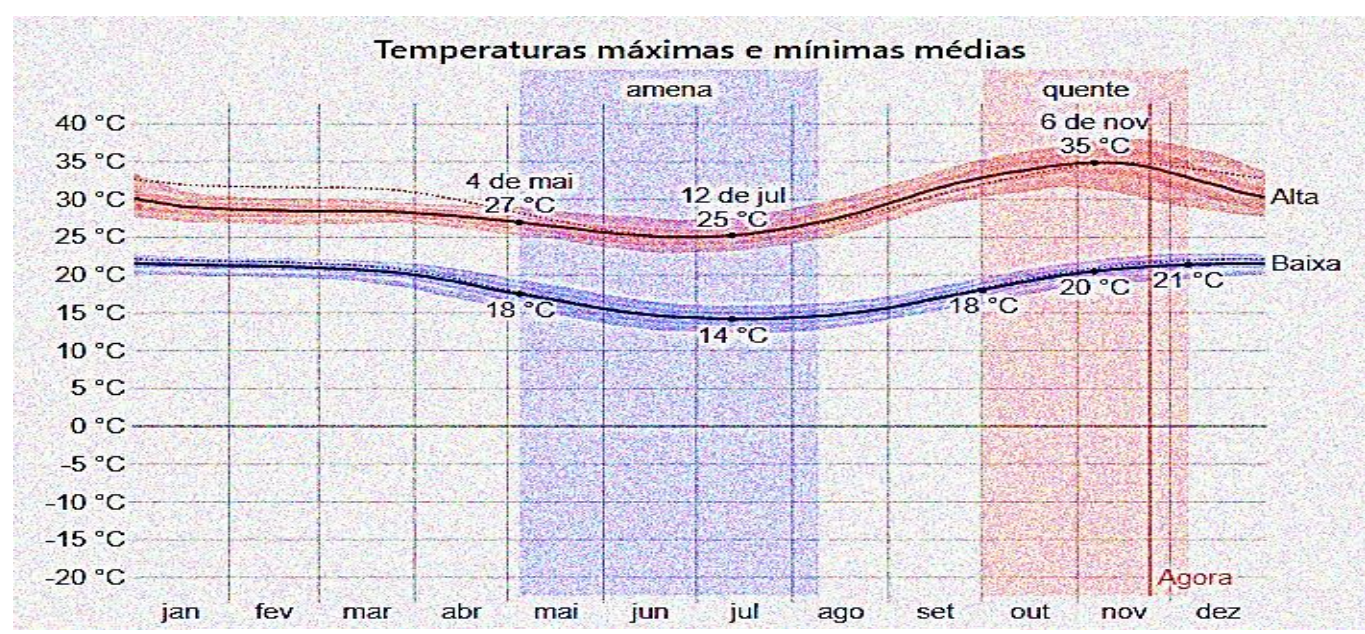

Figura 7: Temperaturas máximas (linha vermelha) e médias (linha azul) no posto administrativo de Anchilo $^{3}$, com faixas de pequenas variações locais.

\subsection{Dimensionamento do sistema}

O dimensionamento do sistema eólico foi feito levando-se em consideração a geração de potência necessária, sem grandes modificações do local (altura do sistema, o raio do rotor, comprimento e número de pás). Considerou-se ainda o material usado (ferro a solda, rolamentos e pás de PVC) para construção de um sistema com eficiência aproximada do sistema convencional.

Mediu-se a tensão e a intensidade da corrente elétrica, usando um multímetro, e com base nos dados calculou-se o valor da potência necessária, utilizando a expressão 5 (tabela 3). Com a potência gerada (tabela 6), fez-se uma relação com a potência nominal dos equipamentos que se pode ligar ao sistema.

Para a análise do funcionamento do aerogerador, foram realizados os testes em três dias diferentes e em dois períodos por dia, nas mesmas horas, utilizando o multímetro e cronómetro, com medições em intervalos de minutos variados, com duração de 60 segundos para cada teste. Em todas as medições, verifica-se uma variação do valor da tensão de saída, mostrando deste modo que em cada medição houve uma variação das condições meteorológicas locais, como a velocidade do vento, a pressão do ar, a temperatura e a umidade do ar (tabela 5).

Fonte: https://pt.weatherspark.com/y/101091/Clima-caracter\%C3\%ADstico-em-NampulaMo\%C3\%A7ambique-durante-o-ano, acesso em 24/11/2020. 
Revista Multidisciplinar do Nordeste Mineiro, v.1,

2021/01

ISSN 2178-6925

Tabela 5: Os parâmetros que contribuíram nos dias de testes

\begin{tabular}{|c|c|c|c|c|}
\hline Dias de testes & $\begin{array}{c}\text { Umidade relativa } \\
\text { do } \operatorname{ar}(\%)\end{array}$ & $\begin{array}{c}\text { Temperatur } \\
\mathrm{a}\left({ }^{\circ} \mathrm{C}\right)\end{array}$ & $\begin{array}{c}\text { Pressão do } \\
\operatorname{ar}(\mathrm{mbar})\end{array}$ & $\begin{array}{c}\text { Velocidade do vento } \\
(\mathrm{m} / \mathrm{s})\end{array}$ \\
\hline Primeiro dia & 76 & 20 & 1020 & 5,2 \\
\hline Segundo dia & 58 & 24 & 1015,9 & 6,7 \\
\hline Terceiro dia & 65 & 22 & 1019,3 & 6,6 \\
\hline Média & 66,3 & 22 & 1018,4 & 6,17 \\
\hline
\end{tabular}

Fonte: Autores, 2020.

As figuras 8 e 9, descrevem o comportamento dos parâmetros medidos durante os testes, em dois períodos por dia.

\section{Relação entre a tensão nos 3 dias de medição}

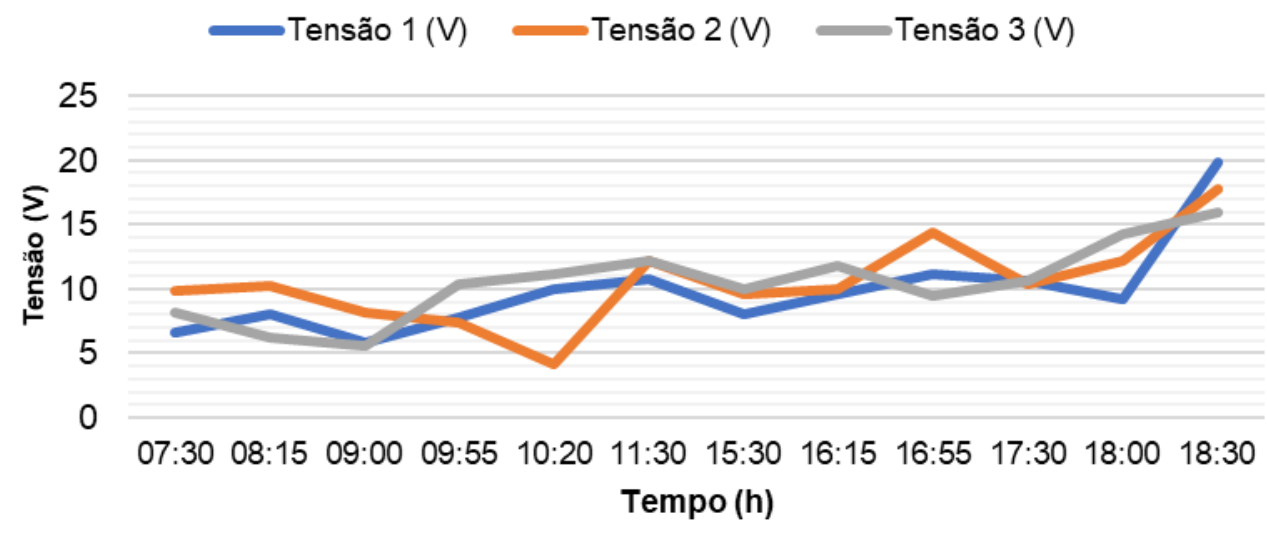

Figura 8: Medição de tensão. Fonte: Autores, 2020.

\section{Relação entre a intensidades da corrente nos 3 dias de medição}

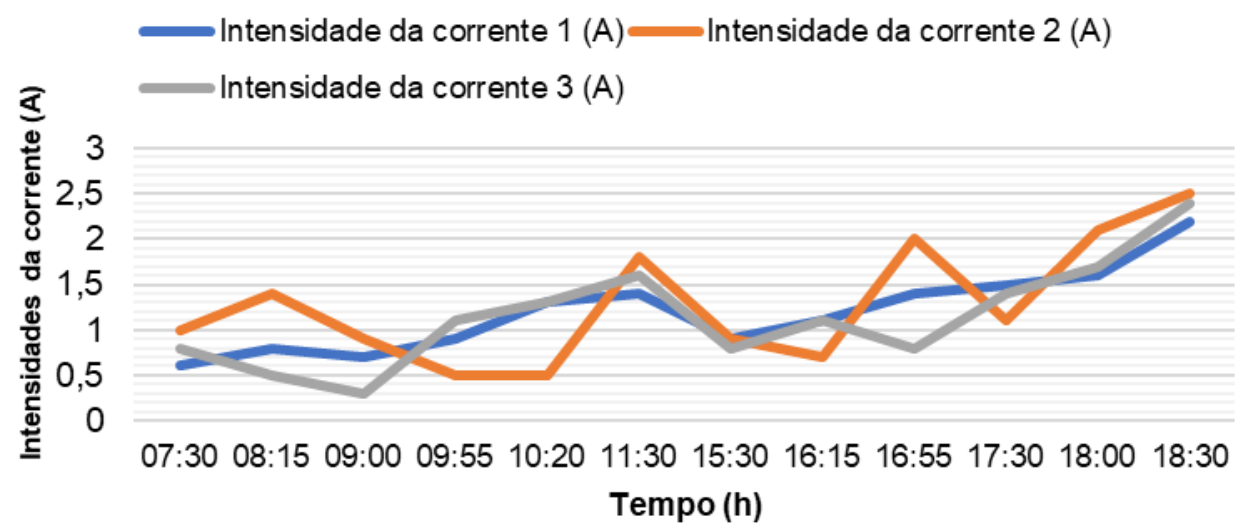

Figura 9: Medição de intensidades da corrente. Fonte: Autores, 2020. 
De acordo com as figuras 8 e 9, observa-se que no segundo dia teve a maior produtividade energética (potência média de 13,52 W) em relação ao primeiro (potência média de 11,74 W) e terceiro dia (potência média de 12,1 W). Fazendo uma correlação dos dados da tabela 5 e as figuras 8 e 9 observa-se que a baixa umidade e pressão do ar tiveram proporcionalidade inversa com as temperaturas do ar e velocidades de vento, influenciando deste modo, na maior geração de eletricidade.

A seguir, usou-se as equações 2, 4, 5 e 6 (tabela 5) para calcular a potência do vento disponível, a potência do rotor, a potência do gerador e o rendimento do sistema, obtendo os valores de $41,3 \mathrm{~W}, 0,015 \mathrm{~W}, 12,4 \mathrm{~W}$ e $30 \%$, respectivamente (tabela 6).

Tabela 6: Parâmetros técnicos no sistema eólico estudado.

\begin{tabular}{|c|c|c|c|}
\hline Grandezas & Vento & Turbina & Gerador \\
\hline Intensidade da corrente $(A)$ & - & - & 1.21 \\
\hline Tensão $(\boldsymbol{V})$ & - & - & 10,266 \\
\hline Potência $(W)$ & 41,3 & - & 12,4 \\
\hline Rendimento $(\%)$ & - & - & 30 \\
\hline Frequência $(H z)$ & - & 0,57 & 1,14 \\
\hline Velocidade de rotação $(r p m)$ & - & 34 & 68 \\
\hline
\end{tabular}

Fonte: Autores (2020)

\subsection{Viabilidade técnica e eficiência}

Durante o período de testes, observou-se que o segundo dia foi o mais produtivo em termos energéticos, por causa das condições climáticas do dia, como a maior velocidade do vento, baixa umidade e temperatura do ar relativamente alta.

A potência gerada e a eficiência do sistema (Tabela 6), foi suficiente para geração de eletricidade para uso doméstico para a comunidade local, em aparelhos de baixa potência como aparelhos sonoros, de rádio e televisão, carregamento de aparelhos celulares e notebook, iluminação com lâmpada LED e fluorescentes, de até pelo menos $12 \mathrm{~W}$, para além de possíveis usos em sistemas de bombeamento de água e de regadio de plantas.

Porém, a baixa eficiência registrada no sistema (30\%) em relação ao sistema convencional (40\%) foi devido ao material utilizado na construção do sistema e 
altura dele. Por isso, para melhorar esse parâmetro é preciso aumentar o número de transformadores, utilizar uma secção maior do fio condutor utilizados na bobinagem dos transformadores durante a construção do gerador, aumentar a altura do sistema em relação ao nível topográfico e diminuir possíveis barreiras que impeçam a circulação a circulação natural do vento.

Por outro, se comparamos a eficiência do sistema em estudo com outros sistemas energéticos usados na comunidade local, como as velas, candeeiros a petróleo, pilhas alcalinas e baterias de chumbo-ácido, verifica-se que o protótipo apresenta alta eficiência relativa, para além de ser mais econômico, a médio e longo prazo e causa menos impactos. Uma análise detalhada em relação às pilhas alcalinas e baterias de chumbo-ácido observa-se que estes sistemas causam mais impactos após o seu uso, sobretudo quando são descartados inadequadamente, podendo contaminar o solo, as águas superficiais e subterrâneas, visto que elas são altamente tóxicas por conterem altos teores de zinco, chumbo e manganês.

\subsection{Viabilidade econômica}

O estudo da viabilidade econômica é de fundamental importância para projetos de energia eólica. Os gastos deste estudo foram divididos entre os custos iniciais e os custos de operação e manutenção. Neste caso, como se trata de apenas uma turbina, os gastos iniciais podem ser resumidos a despesas com avaliação do potencial eólico do local, instalação do aerogerador e custos de equipamentos e componentes. A operação e manutenção são representadas pela manutenção preventiva e possível reposição de componentes, como baterias.

Economicamente, a construção e montagem do sistema não apresentam custos elevados, tendo em conta de que se trata de um sistema construído a partir de materiais alternativos, acessíveis, reciclados e de fácil acesso (Tabela 7). 
Revista Multidisciplinar do Nordeste Mineiro, v.1,

2021/01

ISSN 2178-6925

Tabela 7: Materiais necessários para a construção de um Aerogerador:

\begin{tabular}{|c|c|c|c|}
\hline Nome do material & Quantidade & Custo $\left(\mathrm{MT}^{4}\right)$ & Observação \\
\hline Madeira & 2 & 0,00 & Reciclado \\
\hline Barrotes & 4 & 300,00 & \\
\hline Parafusos & 12 & 120,00 & \\
\hline Imã & 1 & 0,00 & Reciclado \\
\hline Tubo de $1,5 \mathrm{~mm}$ & 1 & 100,00 & \\
\hline Cantoneira & 1 & 150,00 & \\
\hline Rolamentos & 4 & 100,00 & \\
\hline Varão roscado de $10 \mathrm{~mm}$ & 1 & 200,00 & \\
\hline Polias dentadas ou carretos & 2 & 70,00 & \\
\hline Tubo PVC & 1 & 150,00 & \\
\hline Fios de cobre & $1 \mathrm{~kg}$ & 0,00 & Reciclado \\
\hline Núcleo das bobinas do gerador & 3 & 0,00 & Reciclado \\
\hline Varão simples de $8 \mathrm{~mm}$ & 1 & 50,00 & \\
\hline Anilhas & 4 & 0,00 & Reciclado \\
\hline Porcas & 6 & 0,00 & Reciclado \\
\hline \multicolumn{2}{|l|}{ Total } & 1240,00 & \\
\hline
\end{tabular}

Fonte: Autores, 2020.

O sistema analisado é viável sob ponto de vista econômico comparando com o sistema eólico convencional, sabendo que o custo de aquisição de um sistema aerodinâmico convencional, varia de 40.000,00 a 110.000,00 MT, em função do fabricante, dos parâmetros elétricos (potência e tensão gerada), o ruído e a vibração. Por outro lado, quando comparando com os gastos a médio e longo prazo com outros sistemas energéticos de uso local, como o candeeiro a petróleo, velas, baterias ou pilhas alcalinas, o sistema ainda é viável economicamente.

\subsection{Impactos socioambientais}

Durante o funcionamento do sistema houve certo impacto sonoro que não influenciou na qualidade de vida da população e nem da fauna local.

Pelas características e a dimensão do sistema não houve necessidade de deslocar à comunidade, retirar a vegetação e afugentar os animais voadores que frequentam o local. Por isso, não houve necessidade de criar barreiras para preservação da vida dos animais e plantas.

\footnotetext{
${ }^{4}$ Metical é a moeda oficial de Moçambique. Sendo 1 dólar estadunidense equivalente a 74,6 Meticais. Fonte: http://www.bancomoc.mz/fm mercadosmmi.aspx?id=10, acesso em 16/02/2021
} 
Ainda, a área implantada no sistema pode ser usada para prática de agricultura, a caça ou outras práticas que eram realizadas anteriormente no local. Para a comunidade, tem uma importância em melhorar o acesso aos serviços energéticos que possibilita melhorar as condições de vida e a estética do local.

\subsection{Discussão dos resultados}

Segundo a matriz energética local e a possibilidade de geração de eletricidade, a energia eólica é a segunda fonte mais abundante na cidade de Nampula, antecedida da energia solar e seguida da hídrica. Porém, as tecnologias convencionais de aproveitamento dessas fontes de energia, em pequena escala, não apresentam níveis altos de utilização, devido ao elevado custo associado à obtenção do material para a instalação do sistema. Neste contexto, admite-se que é necessário existir sistemas alternativos, de baixos custos e acessíveis, que viabilizem o seu uso.

Um aspecto bastante discutido com Nhamire e Mosca (2014), ALER (2017) e Fortes et al. (2020) e João et al. (2020) referente ao subaproveitamento das energias renováveis, eólica em particular, em Moçambique é a falta de um quadro jurídico, regulador e institucional, falta de financiamento, de competência técnica, de políticas estimulantes e de mecanismos fiscais de difusão das tecnologias e soluções de baixo custo e desenvolvimento de pequenas empresas para conceber, fabricar, distribuir, instalar e gerir as aplicações.

Os fatores acima descritos são agravados pela alta taxa de pobreza e baixo poder de compra, insegurança sociopolítica, serviços de logística e de fornecimento deficientes e pelo fato da maioria da população viver em áreas remotas. Por outro lado, o caráter intermitente e baixa eficiência energética dos aerogeradores devem ser entendidas como fontes complementares, pois, não têm a capacidade de substituir completamente, no atual perfil de oferta existente, os combustíveis fósseis (FORTES et al., 2020; NHAMIRE; MOSCA, 2014).

Analisando as políticas energéticas e ambientais nacionais, os preços da energia da rede nacional e do petróleo, para além da possibilidade de geração de 
energia elétrica a partir da fonte eólica, faz aumentar o interesse na utilização e desenvolvimento de tecnologias alternativas de energia eólica no setor elétrico.

O custo médio para construção e implantação de uma pequena central eólica construído a partir de materiais alternativos é influenciado pelo local de geração em relação aos potenciais consumidores, a possibilidade de conexão em sistemas on grid, a periodicidade e regime do vento, a temperatura, humidade e pressão do ar e as características do aerogerador (PINTO, 2012; SOUZA, 2018).

Para além dos custos dos materiais e serviços apresentados na tabela 7, para as pequenas centrais eólicas podem ser necessários custos adicionais relativos à implantação definitiva do sistema; aos serviços de engenharia (montagem e manutenção dos sistemas); a adequação em função das necessidades dos consumidores finais e da disponibilidade dos recursos. Outro aspecto bastante importante a considerar nas pequenas centrais eólicas para não levar ao superfaturamento dos projetos é a volatilidade dos preços dos materiais alternativos de maiores eficiências e disponíveis no mercado local.

Em função do nível de impactos socioambientais negativos, as pequenas centrais eólicas são atividades classificadas na categoria B no Decreto N 45/2004 de 29 de Setembro (MOÇAMBIQUE, 2004), portanto, exigidos apenas um estudo de impacto ambiental simplificado. Portanto, os principais impactos socioambientais identificados nas pequenas centrais eólicas são: impacto visual, sonoro e possíveis impactos sobre as aves da região.

Em termos econômicos (Tabela 7), a geração eólica de eletricidade a partir de aerogeradores alternativos pode ser uma ótima oportunidade de negócio para microempreendedores no ramo de energia eólica, aos fornecedores dos componentes do sistema, aos revendedores e à população em geral.

Diante disso, a criação e desenvolvimento de tecnologias de aproveitamento de energias limpas e renováveis, em pequena escala, poderá contribuir no desenvolvimento socioambiental e socioeconômico da comunidade. Estas pequenas centrais elétricas segundo João et al. (2020) podem ser desenvolvidas para gerar eletricidade em sistemas acoplados, o equivalente às grandes centrais, sem necessidade de construir linhas de transporte e distribuição de eletricidade. 


\section{Conclusão}

Em vista dos argumentos apresentados sobre aproveitamento de potencial energético das fontes limpas, com baixíssimos impactos socioambientais e disponíveis localmente são evidência suficiente sobre a preocupação na contribuição e na resolução dos problemas ambientais envolvidos na utilização de combustíveis fósseis em Moçambique, sobretudo, nas áreas rurais e suburbanas dos grandes centros populacionais, como a cidade de Nampula.

O posto administrativo de Anchilo apresenta um bom potencial eólico para a geração de energia elétrica em pequena escala, podendo ser usado em sistemas de bombeamento de água e de regadio de plantas.

A potência e a eficiência gerada pelo sistema mostram que este pode ser usado para geração de energia elétrica para pequenos consumidores rurais e em regiões com restrições no fornecimento de ERN ou de forma complementar, e deste modo, minimizar os custos e a dependência da ERN, contribuir na inserção social da população, diminuir a pobreza energética e melhorar o acesso à energia elétrica usando tecnologias sustentáveis e fontes locais. O protótipo pode ser melhorado com vista a responder às reais necessidades dos consumidores.

Da análise feita, concluiu-se que o aerogerador construído com materiais alternativos e implantado próximo às comunidades, apresenta viabilidade técnica, econômica e ambiental na geração de energia elétrica para uso doméstico em pequenos consumidores, em sistemas off grid.

\section{Referências bibliográficas}

ALER. Energias renováveis em Moçambique: Relatório Nacional do ponto de situação. 2. ed. Maputo: Associação Lusófona de Energias Renováveis, 2017.

DUTRA, R. Energia eólica: princípio e tecnologias. Brasilia, DF: CRESESB, 2009. 
FORTES, A. G.; RAIMUNDO, B.; MUTENDA, F. M. Energias renováveis em Moçambique: disponibilidade, geração, uso e tendências futuras. Revista Brasileira Multidisciplinar, v. 23, n. 1, p. 7-27, 2020.

GUEIFÃO, C.; ANDRÉ, J.; NÓBREGA, N.; CARANOVA, R.; SANTOS, J.; ANDRÉ, S.; SOUSA, J.; CÚMANO, G.; ABREU, M.; CHAVES, R.; MORAIS, M.; MARTINS, C.; ROSA, F.; MENDONÇA, B.; SANSANA, J.; SANTOS, P.P. D.; FALCÃO, D. Atlas das energias renováveis de Moçambique: Recursos e projectos para produção de electricidade. 1. ed. Maputo: Gesto-Energia, S.A., 2013.

JOÃO, A. A.; FORTES, A.G.; RICHADE, C. P.; ALFACE, P. B.; FERNANDO, E. T.; $\mathrm{CHAU}, \mathrm{M}$. J. Sustentabilidade socioambiental e impactos na geração hidroelétrica nos pequenos potenciais hídricos no rio Muatala, Nampula Moçambique. II Sustentare e V WIPIS. Anais...Campinas, SP: Agência das bacias PCJ, 2020

KEMERICH, P. D. D.; UCKER, F. E.; FOLETTO, C. V.; ROSA, L. M. Avaliação de impactos ambientais na implantação e operação de Olaria. Engenharia Ambiental - Espírito Santo do Pinhal, v. 8, p. 134-150, 2011.

MARTINS, F. R.; GUARNIERI, R. A.; PEREIRA, E. B. O aproveitamento da energia eólica. Revista Brasileira de Ensino de Física, v. 30, n. 1, p. 1-13, 2008.

MOÇAMBIQUE. Lei 20/1997, de 1 de Outubro. Lei do Ambiente. Maputo: Boletim da República de Moçambique, 1997.

MOÇAMBIQUE. Decreto $n^{\circ}$ 45/2004 de 29 de Setembro: Regulamento sobre o processo de avaliação de impacto ambiental. Maputo: Boletim da República de Moçambique, 2004.

NHAMIRE, B.; MOSCA, J. Electricidade de Moçambique: mau serviço, não transparente e politizada. Maputo: Centro de Integridade Pública de Moçambique, 
2014.

PINTO, O. Fundamentos de Energia Eólica. 1. ed. Rio de Janeiro, RJ: LTC, 2012. REIS, L. B. DOS. Matrizes energéticas: conceitos e usos em gestão e planejamento. 1. ed. Barueri - SP: Editora Manole, 2011.

SILVA, E. M. DA; BANGA, N. M.; ALVES, J. M. B. Modelagem dos Recursos Eólicos sobre Moçambique Considerando um Cenário de Mudanças Climáticas. Revista Brasileira de Meteorologia, v. 2, n. 1, p. 157-170, 2017.

SILVA, N. F. DA. Fontes de energia renováveis complementares na expansão do setor elétrico brasileiro: o caso da energia eólica. Dissertação de Mestrado em Planejamento Energético. Universidade Federal do Rio de Janeiro. Rio de Janeiro - RJ, 2006.

SOUSA, I. D. P. DE. Projeto e ensaios de pás para turbinas eólicas de pequeno porte com diferentes correções geométricas na ponta e na raiz da pá. Dissertação de Mestrado em em Engenharia Mecânica. Universidade Federal do Ceará. Fortaleza - CE, 2014.

SOUZA, S. F. DE. Análise e simulação de turbinas eólicas de eixo vertical (Darrieus e Lenz2) e horizontal para o dimensionamento de geradores elétricos. Dissertação de Mestrado em Engenharia Elétrica. Universidade Federal de Mato Grosso do Sul. Campina Grande - MS, 2018. 